DOI: https://doi.org/10.11144/Javeriana.umed60-3.mult

\title{
Implementation of a Multimodal Analgesic Strategy Including Continuous Femoral Nerve Block in Patients Undergoing Total Knee Arthroplasty
}

\section{Implementación de una estrategia de analgesia multimodal que incluye el bloqueo continuo del nervio femoral en pacientes llevados a remplazo primario total de rodilla}

Received: 09/01/2019 | Accepted: 26/03/2019

\author{
Reinaldo Grueso Angulo \\ Pontificia Universidad Javeriana, Colombia \\ Antonio José Bonilla Ramírez \\ Pontificia Universidad Javeriana, Colombia \\ Milena Moreno Oliveros \\ Pontificia Universidad Javeriana, Colombia \\ Diego Moreno \\ Pontificia Universidad Javeriana, Colombia \\ Diego Quesada \\ Pontificia Universidad Javeriana, Colombia \\ Laura Abril \\ Pontificia Universidad Javeriana, Colombia \\ María Cristina Mondragón \\ Pontificia Universidad Javeriana, Colombia \\ Ana María Matamoros \\ Pontificia Universidad Javeriana, Colombia
}

a Correspondencia: rgrueso@husi.org.co

How to cite: Grueso Angulo R, Bonilla Ramírez AJ, Moreno Oliveros M, Moreno D, Quesada D, Abril L, Mondragón MC, Matamoros AM. Implementation of a multimodal analgesic strategy including continuous femoral nerve block in patients undergoing total knee arthroplasty. Univ. Med. 2019;60(3). https://doi.org/1 0.11144/Javeriana.umed60-3.mult

\begin{abstract}
Total knee replacement is a painful surgical procedure. The inadequate control of postoperative pain is associated with adverse outcomes in the short and long term. Continuous femoral block has been shown to be effective and efficient as part of multimodal analgesia. This series of 48 patients who underwent total knee replacement, who received multimodal analgesic treatment including continuous femoral nerve block, documents the pain control profile during the first 48 hours. This is a successful experience of implementing regional techniques as part of perioperative pain relief, as documented in the literature. We emphasize that each institution must know its technical and human resource and characterize its patients, in order to implement multimodal analgesia protocols that include this regional technique. We also suggest to monitor and implement continuous improvement processes.

Keywords

contiuous femoral nerve block; multimodal analgesia; perioperative analgesia; knee arthroplasty.
\end{abstract}




\section{RESUMEN}

El remplazo total de rodilla es un procedimiento quirúrgico doloroso. El inadecuado control del dolor postoperatorio se asocia a desenlaces adversos a corto y largo plazo. El bloqueo femoral continuo ha demostrado ser eficaz y eficiente como parte de la analgesia multimodal. Esta serie de 48 pacientes sometidos a remplazo total de rodilla, quienes recibieron tratamiento analgésico multimodal, incluyendo bloqueo continuo de nervio femoral, documenta el perfil de control del dolor durante las primeras 48 horas. Esta es una experiencia exitosa de implementación de técnicas regionales como parte del alivio del dolor perioperatorio, como es documentado en la literatura. Hacemos énfasis en que cada institución debe conocer su recurso técnico y humano, y caracterizar a sus pacientes, para poder implementar protocolos de analgesia multimodal que incluyan esta técnica regional. Así mismo sugerimos hacer un seguimiento e implementar procesos de mejoramiento continuo.

Palabras clave

bloqueo continuo del nervio femoral; analgesia multimodal; analgesia perioperatoria; remplazo total de rodilla.

\section{Introduction}

Total knee replacement is the best available treatment for severe gonarthosis. Despite advances in surgical technique, postoperative pain is one of the main associated problems, with a prevalence of moderate pain of $52 \%$ and of severe pain of up to $16 \%$, at 30 days after the procedure $(1,2)$.

Optimal analgesia promotes early mobility, which accelerates functional recovery, increases the scores on satisfaction scales and decreases the length of hospital stay $(3,4)$. On the other hand, acute postoperative pain is associated with negative short- and long-term outcomes (5).

Non-pharmacological and pharmacological approaches, and peripheral neuroaxial and regional techniques initiated before and continued during and after the procedure, have demonstrated effectiveness in relieving postoperative pain in total knee arthroplasty (6). Regional analgesia techniques have been proposed as strategies aimed at improving postoperative pain control, reducing opioid consumption and optimizing the patient's rehabilitation profile.

Continuous or single shot femoral nerve block is one of the regional techniques with greater evidence of good quality that has shown similar effectiveness to that of epidural analgesia, better pain relief, and fewer side effects associated with opioid use compared with placebo and with opioid systemic analgesia $(7,8,9,10,11,12)$. Because of this, femoral nerve block is one of the peripheral regional analgesic techniques recommended in total knee arthroplasty (13).

\section{Materials and methods}

\section{Type of study}

The protocol of this prospective observational study with an analytical component was approved by the Ethics and Research Committee of the Hospital Universitario San Ignacio. The informed consent of the patients included was obtained before the procedure. The data was collected during the daily follow-up, through a personalized interview and filling in forms.

\section{Patients}

Data were collected from ASA I to III adult patients who underwent total knee replacement after being diagnosed with gonarthrosis, between February 2015 and February 2017. Patients contraindicated for continuous femoral nerve block as an analgesic technique (coagulation disorders, anticoagulant use or puncture site infection), as well as those with daily opioid consumption in the two weeks prior to the procedure or a history of chronic opioid use were excluded.

\section{Intervention (continuous femoral nerve block)}

The catheter was inserted before the anesthetic induction, under basic monitoring, with supplementary oxygen and conscious sedation with a single 50 to $100 \mu \mathrm{g}$ dose of fentanyl or 1 to $2 \mathrm{mg}$ of midazolam until achieving a comfortable state. After performing asepsis and antisepsis, a high frequency linear transducer was used in the axial axis to identify the vein, the artery and the femoral nerve in the short axis, distal to the 
inguinal ligament and proximal to the inguinal fold. The fascia of the iliac muscle was identified and, under direct ultrasound vision, an in-plane (lateral to medial) puncture was made toward the femoral nerve with a NanoLong Touhy 18 $\mathrm{G}$ needle. $20 \mathrm{~cm}^{3}$ of $0.125 \%$ bupivacaine with epinephrine were administered. The catheter (StimuLong Sono of PAJUNK® 20 G) was advanced and fixed to the skin.

\section{Anesthetic technique}

Patients received spinal anesthesia with $0.5 \%$ heavy bupivacaine, with or without $20 \mu \mathrm{g}$ of intrathecal fentanyl or general anesthesia using fentanyl, propofol and cisatracurium, and anesthetic maintenance with sevoflorane and remifentanil.

\section{Multimodal analgesia}

All patients received an intraoperative single dose of dexamethasone and dipyrone or diclofenac. In the post-anesthesia care unit (PACU), infusion of $0.125 \%$ bupivacaine was started at $5-7 \mathrm{~cm} 3 / \mathrm{h}$, through the perineural femoral catheter and continued until postoperative day 2 .

During the procedure, the surgeon performed periarticular infiltration of the posterior capsule of the knee, before facing the tibial and femoral components, and after the osteotomies. From the first postoperative day, all patients received $1 \mathrm{~g}$ of acetaminophen orally (PO) every $8 \mathrm{~h}$ and $250 \mathrm{mg}$ of naproxen $\mathrm{PO}$ every $8 \mathrm{~h}$, associated with gastric protection. Additionally, they received $1.25 \mathrm{mg}$ of hydromorphone $\mathrm{PO}$ (every $8 \mathrm{~h}$ in those over 65 years of age, and every $6 \mathrm{~h}$ in those under 65 years of age). In case of need, rescue doses of 1.25 $\mathrm{mg}$ of hydromorphone $\mathrm{PO}$ were used (maximum 6 a day).

Incidental pain of the anterior region of the knee was treated administering $7 \mathrm{~cm} 3$ boluses of local anesthetic through the perineural femoral catheter and the infusion was adjusted according to pain control and the presence of motor block.
In case of incidental pain in the posterior region of the knee, rescue morphine or hydromorphone in equipotent doses were administered.

\section{Items evaluated}

Pain was evaluated using the visual analogue scale (VAS) from 0 to $10(0=$ no pain, 10 = severe pain), in the PACU before initiating the local anesthetic infusion through the femoral perineural catheter, at 24 and 48 postoperative hours. A VAS score of 4 or higher was considered significant pain (10).

Cumulative opioid consumption in milligram equivalents of intravenous morphine $(1 \mathrm{mg}$ of hydromorphone $=5 \mathrm{mg}$ of morphine, IV $\mathrm{mg}$ $\times 3=\mathrm{mg}$ PO) and the presence of adverse effects associated with the use of opioids such as nausea and vomiting, urinary retention, itching and respiratory depression were documented.

The fulfillment of physical rehabilitation goals was measured; these included independent ambulation with a walker, flexion up to 45 degrees at 24 hours and up to 70 degrees at 48 hours and extension to zero degrees at 24 and 48 hours.

The presence of complications associated with the perineural catheter and complications associated with the use of local anesthetics, such as neurotoxicity and cardiotoxicity, was recorded.

VAS pain assessment was considered a discrete variable, and opioid consumption was considered a continuous variable. These variables were expressed in averages with standard deviation or with range, as appropriate. Goal fulfillment and the presence of opioid adverse effects were expressed as percentage of patients.

\section{Results}

Data were collected from 48 patients who met the inclusion and exclusion criteria. The demographic data are presented in Table 1. 
Table 1

Characteristics of the population

\begin{tabular}{|l|r|}
\hline & $\mathbf{n}=\mathbf{4 8}$ \\
\hline Women/Men & $34(70 \%) / 14(30 \%)$ \\
\hline Age & $71.8[9.4]$ \\
\hline Spinal/general & $35(73 \%) / 13(27 \%)$ \\
\hline $\begin{array}{l}\text { Spinal anesthesia: } \\
\text { intrathecal opioid/non- } \\
\text { intrathecal opioid }\end{array}$ & $20(41 \%) / 28(59 \%)$ \\
\hline
\end{tabular}

Note:the average is given in percentages and the standard deviation appears in square brackets [].

During the PACU stay, $66.7 \%$ of the patients had adequate pain control; the average VAS score was lower in the patients who received spinal anesthesia than in those who received general anesthesia (2.6 vs 6.1). At 24 hours postoperatively, $47.9 \%$ of patients had adequate dynamic pain control, and at 48 hours postoperatively, $64.5 \%$ of patients had adequate dynamic pain control (Table 2).

Table 2

Pain assessment using the Visual Analogue Scale

\begin{tabular}{|c|c|c|c|}
\hline & \begin{tabular}{|c|} 
PACU (at \\
rest)
\end{tabular} & $\begin{array}{l}24 \text { hours } \\
\text { (while } \\
\text { moving) }\end{array}$ & $\begin{array}{l}48 \text { hours } \\
\text { (while } \\
\text { moving) }\end{array}$ \\
\hline Less than 4 & $\begin{array}{r}32(66.7 \\
\%\end{array}$ & $23(47.9 \%)$ & $31(64.5 \%)$ \\
\hline $\begin{array}{l}\text { Greater than or } \\
\text { equal to } 4\end{array}$ & $\begin{array}{r}16(33.3 \\
\%) \\
\end{array}$ & 25 (52.1\%) & $17(35.5 \%)$ \\
\hline $\begin{array}{l}\text { Average using } \\
\text { VAS } \\
\text { general/spinal }\end{array}$ & $\begin{array}{c}3.5[3.3] \\
6.1 / 2.6\end{array}$ & $3.8[2.6]$ & $2.9[1.9]$ \\
\hline
\end{tabular}

Note:the average is given in percentages and the standard deviation appears in square brackets [].

The average cumulative opioid consumption at $24 \mathrm{~h}$ postoperatively was $12 \mathrm{mg}$ of intravenous (IV) morphine, with a 0-23 $\mathrm{mg}$ range, and the average at $48 \mathrm{~h}$ postoperatively was $24 \mathrm{mg}$ of IV morphine (Table 3).
Table 3

Opioid consumption and functional recovery (the average is expressed in range and percentage)

\begin{tabular}{|l|r|r|}
\hline & \multicolumn{1}{|c|}{ 24 hours } & \multicolumn{1}{|c|}{ 48 hours } \\
\hline & Opioid consumption \\
\hline $\begin{array}{l}\text { Average daily consumption } \\
\text { Average cumulative } \\
\text { consumption }\end{array}$ & $12(0-23)$ & $12(0.5-25)$ \\
\hline \multicolumn{3}{|c|}{ Rehabilitation goals } \\
\hline Ambulation & $20(41.7 \%)$ & $39(81.25 \%)$ \\
\hline Flexion & $34(70.8 \%)$ & $29(60.4 \%)$ \\
\hline Extension & $19(39.6 \%)$ & $10(20.8 \%)$ \\
\hline
\end{tabular}

Regarding the fulfillment of the rehabilitation goals, $41.7 \%$ of the patients achieved the goal of independent ambulation with walker at 24 $\mathrm{h}$ postoperatively, and $81.3 \%$ of the patients achieved it at $48 \mathrm{~h}$ postoperatively. $70.8 \%$ of patients met the flexion goal, and 39.6\% of patients met the extension goal at $24 \mathrm{~h}$ postoperatively. At $48 \mathrm{~h}$ postoperatively, $60.4 \%$ and $20.4 \%$ of patients achieved the flexion and extension goal, respectively.

Two of the patients had the catheter removed due to accidental displacement at $24 \mathrm{~h}$ postoperatively. The rest of the patients continued with the catheter for at least $48 \mathrm{~h}$.

$39.6 \%$ of the patients presented opioidassociated adverse effects at $24 \mathrm{~h}$ postoperatively. Nausea and vomiting was the most common, in $50 \%$ of cases. There were no complications associated with the use of the catheter or the use of local anesthetics. A $48 \mathrm{~h}$ follow-up was carried out in all the patients included in the study.

\section{Discussion}

Due to the complexity of knee innervation and the severity of the pain associated with total knee replacement, it is not yet clear what is the ideal analgesic strategy. The current recommendation is to use multimodal analgesia protocols that include peripheral regional techniques, some of which are epidural analgesia, lumbar plexus block, continuous femoral and sciatic block, continuous femoral block, blockade of the adductor canal and periarticular infiltration with local anesthetic (13). One of the most effective strategies from the analgesic point of view is continuous femoral and sciatic block. However, 
it is necessary to balance the analgesic needs with the preservation of muscle strength, which allows the initiation of early rehabilitation, so that the real benefit of this regional technique remains controversial (14). On the other hand, there is no convincing evidence showing that blockade of the adductor canal, which seeks to preserve the quadriceps motor function, reduces the risk of falling after total knee arthroplasty $(15,16)$.

Randomized clinical trials and meta-analyzes support that continuous femoral nerve block is superior to placebo and systemic opioid analgesia in terms of pain control, time to first opioid dose, requirement for supplementary analgesia, total opioid consumption, opioid use side effects and functional outcomes. Likewise, compared with neuroaxial techniques, it has proved not to be inferior in terms of pain control, but with better functional outcomes.

One of the outcomes used in published studies to measure the effectiveness of continuous femoral nerve block is the percentage of patients with significant dynamic pain at 24 $\mathrm{h}$ postoperatively, which is around $60 \%$, with an average pain level measured by numerical scales that goes from 2 to 4 . Another outcome is cumulative opioid consumption, which shows an important heterogeneity between the studies, with postoperative consumptions ranging between 2.5 and $16 \mathrm{mg}$ at $24 \mathrm{~h}$, and 8 to $20 \mathrm{mg}$ at $48 \mathrm{~h}$. Likewise, several publications have reported the presence of opioid use side effects, which occur in $7.5 \%$ to $10.5 \%$ of patients.

Our results show that the percentage of patients with adequate dynamic pain control at 24 and 48 postoperative hours and the cumulative opioid consumption were similar to those recorded in the literature, with a frequency of adverse effects to the use of opioids three times greater than that reported in previous studies. In reviewing the opioid administration schemes, we found that the studies use PCA systems, while in our case we use schedule schemes with the possibility of rescues, a fact that favors the administration of unnecessary doses of opioids.

Regarding the rehabilitation profile, the percentage of patients who reached the goal of independent ambulation doubled between hour
24 and hour 48. However, the percentage of patients who achieved the goal of extension and flexion did not follow the same pattern, without affecting the goal of independent ambulation. This is explained by base conditions of the knee joint or by joint inflammation phenomena. These results are not comparable with the evidence published so far, because the time of measurement and the goals vary widely among the studies. It would be worth establishing protocols to standardize interventions and their evaluation, in order to make objective comparisons in later studies.

None of the patients presented mechanical complications associated with the perineural catheter or complications associated with the use of local anesthetics, which suggests that continuous femoral nerve block is a safe technique. However, we believe that close monitoring is necessary throughout the postoperative period, to ensure the safety of patients managed with continuous peripheral regional techniques that involve the use of perineural catheters.

The present study is limited by the lack of randomization, which predisposes to the appearance of biases. Likewise, the sample size was small, which decreases the study power. In addition, the anesthetic technique was not standardized. Although intrathecal opioid spinal anesthesia has shown benefits in some studies, the evidence is not conclusive. The follow-up was limited to the duration of the perineural catheter, so it was not possible to describe the behavior of the outcomes after 48 hours postoperatively. The absence of a control group does not allow comparisons and makes it difficult to measure effectiveness. With the results obtained it is not possible to recognize which elements related to the anesthetic technique or the multimodal analgesic strategy had a positive impact on the postoperative outcomes. Due to the above, it is necessary to carry out future studies with standardized management protocols to evaluate the impact of each element of the multimodal analgesia protocols on short, medium and long term outcomes. 
Although with some differences, the results of our study are similar to those of previous studies, so we believe that, in general, it is possible to reproduce the benefits reported in the literature by including the femoral nerve block within a multimodal analgesia strategy. It is important to know that in order to implement multimodal analgesia protocols, it is necessary to promote training and communication within the health care team made up of surgeons, anesthesiologists, nurses and rehabilitation team, standardize evidence-based practices, perform close monitoring of the interventions, measure the outcomes and disseminate the results obtained over time. Each institution must know its resources, characterize its patients and measure their outcomes, to implement protocols in conformity with its particular conditions, and develop processes to achieve continuous improvement that allow adjustments in its daily practices, in order to improve the recovery of patients.

\section{References}

1. Murphy L, Schwartz TA, Helmick CG, Renner JB, Tudor G, Koch G, et al. Lifetime risk of symptomatic knee osteoarthritis. Arthritis Rheum. 2008;59(9):1207-13. https://doi.org/10 $.1002 /$ art.24021.

2. Grosu I, Lavand'homme P, Thienpont E. Pain after knee arthroplasty: an unresolved issue knee surgery. Knee Surg Sports Traumatol Arthrosc. 2014;22(8):1744-58. https:// doi.org/10.1007/s00167-013-2750-2.

3. Chelly JE, Greger J, Gebhard R, Coupe K, Clyburn TA, Buckle R, et al. Continuous femoral blocks improve recovery and outcome of patients undergoing total knee arthroplasty. J Arthroplast 2001;16(4):436-45.

4. Capdevila X, Barthelet Y, Biboulet P, Ryckwaert Y, Rubenovitch J, d'Athis F. Effects of perioperative analgesic technique on the surgical outcome and duration of rehabilitation after major knee surgery. Anesthesiology [internet]. 1999;(91):8-15. Avalaible from: https://pdfs.semanticscholar.org/ 31d4/e3d1eda3b999431cf4558453ee8 459c3571e.pdf

5. Parvizi J, Miller AG, Gandhi K. Multimodal pain management after total joint arthroplasty. J Bone Joint Surg Am. 2011;93(11):1075-84. https: //doi.org/10.2106/JBJS.J.01095

6. Horlocker TT. Pain management in total joint arthroplasty: a historical review. Orthopedics. 2010;33(9 Suppl):14-9.

7. Singelyn FJ, Deyaert M, Joris D, Pendeville E, Gouverneur JM. Effects of intravenous patient-controlled analgesia with morphine, continuous epidural analgesia, and continuous three-in-one block on postoperative pain and knee rehabilitation after unilateral total knee arthroplasty. Anesth Analg. 1998;87(1):88-92.

8. Ganapathy S, Wasserman RA, Watson JT, Bennett J, Armstrong KP, Stockall CA, et al. Modified continuous femoral three-in-one block for postoperative pain after total knee arthroplasty. Anesth Analg 1999;89(5):1197-202.

9. Seet E, Leong WL, Yeo AS, Fook-Chong S. Effectiveness of 3-in-1 continuous femoral block of differing concentrations compared to patient controlled intravenous morphine for post total knee arthroplasty analgesia and knee rehabilitation. Anaesth Intensive Care. 2006;34(1):25-30.

10. Chan EY, Fransen M, Sathappan S, Chua NH, Chan $\mathrm{YH}$, Chua $\mathrm{N}$. Comparing the analgesia effects of single-injection and continuous femoral nerve blocks with patient controlled analgesia after total knee arthroplasty. J Arthroplasty. 2013;28(4):608-13. 
11. Ey C, Fransen M, Parker DA, Assam PN, Chua N. Femoral nerve blocks for acute postoperative pain after knee replacement surgery. Cochrane Database Syst Rev. 2014; (5):CD009941. https://doi.org/10.1002 /14651858.CD009941.pub2.

12. Paul JE, Arya A, Hurlburt L, Cheng J, Thabane L, Tidy A, et al. Femoral nerve block improves analgesia outcomes after ttal kee arthroplasty. Anesthesiology. 2010;103(5):1144-62.

13. Terkawi YS, Mavridis D, Sessler DI, Nunemaker MS, Doais KS, Terkawi RS, et al. Pain management modalities after total knee arthroplasty: a network meta-analysis of 170 randomized controlled trials. Anesthesiology. 2017;126(5):923-37. https://doi.org/10 $.1097 /$ ALN.0000000000001607.

14. Ilfeld BM, Madison SJ. The sciatic nerve and knee arthroplasty to block, or not to block $\mathrm{V}$ that is the question. Anethes Pain Med. 2011;36(5):421-3.

15. Hussain $\mathrm{N}$, et al. Adductor canal block versus femoral nerve block for total knee arthroplasty. Anesthesiology. 2014;120(3):540-50.

16. Elkassabany NM, Antosh S, Ahmed M, Nelson C, Israelite C, Badiola I, et al. The risk of falls after total knee arthroplasty with the use of a femoral nerve block versus an adductor canal block: a double-blinded randomized controlled study. Anesth Analg. 2016;122(5):1696-703. https://doi.org/ 10.1213/ANE.0000000000001237. 